\title{
Studies on carotenoids in watermelon flesh
}

\author{
Wen'en Zhao ${ }^{1,2^{*}}$, Pin $\mathrm{Lv}^{1}$, Huihui $\mathrm{Gu}^{3}$ \\ ${ }^{1}$ School of Chemical Engineering and Energy, Zhengzhou University, Zhengzhou, China; \\ *Corresponding Author: zhaowenen@edu.zzu.cn \\ ${ }^{2}$ Zhengzhou Fruit Research Institute, Chinese Academy of Agricultural Sciences, Zhengzhou, China \\ ${ }^{3}$ Department of Bioengineering, Zhengzhou University, Zhengzhou, China
}

Received 27 April 2013; revised 1 June 2013; accepted 30 June 2013

Copyright (C) 2013 Wen'en Zhao et al. This is an open access article distributed under the Creative Commons Attribution License, which permits unrestricted use, distribution, and reproduction in any medium, provided the original work is properly cited.

\begin{abstract}
Carotenoids are responsible for the different flesh colors in watermelon fruit, such as white, salmon yellow, orange, pale yellow, canary yellow, crimson red, and scarlet red. In red-fleshed watermelons lycopene constitutes the major pigment and $\beta$-carotene the secondary. The predominant carotenoid in yellow-fleshed watermelon is neoxanthin. Lycopene content in watermelon is related to genotype and ploidy level, harvest maturity, and growth and development conditions. Watermelon flesh colors are controlled by several gene loci. There are two or three alleles identified at each gene locus. Up to now several full-length cDNAs or gene fragments encoding enzymes in the carotenoid metabolic pathway have been isolated and characterized from mature watermelon fruits. Differential expression of carotenogenic genes was examined in flesh, ovary, leaf, and root tissues across different colored fleshes (white, canary yellow, salmon yellow, orange, and red). Carotenogenic gene expression was also analyzed at three fruit developmental stages $(10,20$, and 30 days postanthesis) in five flesh colors of watermelon cultivars (red, pink, orange, yellow, and white).
\end{abstract}

Keywords: Watermelon; Carotenoid; Determination; Genes and Their Expression

\section{INTRODUCTION}

Watermelon is the third most popular fruit vegetable in the world and also the largest among the fruits eaten in hot weather. Flesh color is an important trait of watermelon. There are now eight designated flesh colors in watermelon: white, salmon yellow, orange, crimson red, scarlet red, pale yellow, canary yellow and green [1]. Watermelon contains diverse carotenoids that are responsible for the different flesh colors except green flesh color. Like in other fruits and vegetables, carotenoids are main functional components and micronutrients in watermelon. Investigation of carotenoid composition and content, and its metabolic pathway in watermelon should become an important field of watermelon breeding for quality estimation and nutrition breeding.

\section{CAROTENOID COMPOSITION AND CONTENT IN DIFFERENT FLESH-COLORED WATERMELON}

Open-column chromatography (OCC) was used commonly in early separative and measuring studies on various carotenoids in watermelon. Nowdays high performance liquid chromatography (HPLC) technique has come into use in carotenoid analysis in watermelon. It was reported that red-fleshed watermelons consisted of mostly lycopene and $\beta$-carotene. Prolycopene, phytoene, and $\zeta$-carotene were major pigments in orange-fleshed watermelon. An experimental orange-fleshed water melon cultivar "NY162003" contained mostly $(>99 \%) \beta$ carotene and only traces of lycopene [2]. Perkins-Veazie analyzed carotenoid concentration profiles of red-fleshed watermelon using HPLC and $\mathrm{C}_{30}$ column [3]. Lycopene provided the largest portion of the total carotenoids (84\% - 97\%). cis-Lycopene (predominately 5-cis-lycopene) was $2 \%-18 \%$ of the total lycopene. $\beta$-Carotene and phytofluene made up $2 \%-11 \%$ and $0.5 \%-7 \%$ of the total carotenoids respectively. Phytoene, $\gamma$-carotene, and $\zeta$-carotene were present but too low to quantify. $1 \%-2 \%$ $\mathrm{mg} / \mathrm{kg}$ lutein was found in other watermelon studies using a $\mathrm{C}_{18}$ column but lutein peak was unable to be resolved under their conditions using a $\mathrm{C}_{30}$ column. Neurosporene peak also could not be resolved using their conditions.

In our laboratory the carotenoids were separated by 
open column chromatography from red-, yellow-, coral-, pink-, and white-fleshed cultivars of watermelons and were identified by the position on the column and the color of the pigment bands, their absorption spectra, and the characteristic shapes or fine structure of their spectra (Table 1). HPLC (HPLC column: Vydac 201TP54, 25 $\mathrm{cm} \times 4.6 \mathrm{~mm}$ ) was used in the quantitative analysis of carotenoids in the five different flesh colored watermelon cultivars (Table 2). The results showed that the compositional profiles of carotenoids were identical in "Zaohua", "96B41" and "Hongyihao", with lycopene constituting the major pigment and $\beta$-carotene constituting the secondary. Carotenoids were not detectablen with HPLC in "Sanbai" fruit, however, phytofluene, $\zeta$-carotene and $\beta$ carotene were isolated by OCC. Similarly, HPLC analysis showed only the peak corresponding to neoxanthin, the major pigment, and unknown pigment peak in "307 Chaofeng", whereas OCC also identified the presence of phytofluene, $\zeta$-carotene, lycopene, and $\beta$-carotene. The differences in carotenoid detection between OCC and HPLC may be due to the small amounts of certain carotenoids which are below the detection limit of HPLC [4, 5].To the best of our knowledge this is first report regarding neoxanthin, as a the dominant carotenoid, in yellow-fleshed watermelon [5-7]. Bang also reported the predominant carotenoid in canary yellow-fleshed watermelon was neoxanthin, followed by violaxanthin and neochrome [8]. Afterwards, Liu reported that lycopene was the dominant carotenoid in the watermelons with red flesh, such as all-trans lycopene accounted for $67 \%$ of the total carotenoids in the cultivar of "Xiaohongyu (XR)" to $84 \%$ in the cultivar of "Nongkangxianfeng
(NR)", and the concentration of all-trans lycopene varied largely from $705.20 \pm 59.90$ to $2004.51 \pm 178.80 \mu \mathrm{g} / \mathrm{g}$ dry weight (d.w.) [9]. Small amounts of phytoene, phytofluene, $\zeta$-carotene $\alpha$-carotene, all-trans lutein all-trans zeaxanthin, and all-trans violaxanthin were also present in all the watermelons with red flesh. "Ju-Bao (JBOY)" with orange-yellow flesh contained $\beta$-carotene $(860.50 \pm$ $135.54 \mu \mathrm{g} / \mathrm{g}$ d.w.), the most abundant carotenoid, and trace amounts of all-trans lycopene, cis-13-lycopene, alltrans lutein, phytoene, phytofluene, and $\zeta$-carotene. All-tran violaxanthin, 9-cis-violaxanthin, and luteoxanthin were the dominant carotenoids in the yellow-flesh watermelons and accounted for $82.87 \%-89.99 \%$ of the total carotenoids $(20-30 \mu \mathrm{g} / \mathrm{g}$ d.w.). Trace amounts of carotenoids were phytoene, all-trans lutein, and $\beta$-carotene. Hui and Li reported that the carotenoid contents of red-flesh watermelon and yellow-flesh watermelon were $0.3432 \mathrm{mg} / \mathrm{g} \mathrm{dw}$ and $0.1167 \mathrm{mg} / \mathrm{g} \mathrm{dw}$, respectively [10]. In the former lycopene accounted for $94.7 \%$ and $\beta$-carotene $5.3 \%$, in the later lutein and lycopene made up $12.16 \%$.

Watermelon exhibits a number of flesh color types and therefore, has different carotenoid patterns. The composition and content of carotenoids in watermelons with various flesh colors are associated with cultivars and cultivated environments.

\section{INFLUENTIAL FACTORS ON LYCOPENE CONTENT IN WATERMELON}

Study on lycopene in watermelon has been paid close

Table 1. Identification of all carotenoid zones separated from five watermelon cultivars on open chromatographic column.

\begin{tabular}{|c|c|c|c|c|c|c|}
\hline \multirow{2}{*}{ Code name of cultivar } & \multicolumn{6}{|c|}{ components } \\
\hline & 1 & 2 & 3 & 4 & 5 & 6 \\
\hline Zaohua (red) & phytofluene & $\beta$-carotene & lycopene & $\zeta$-carotene & $\gamma$-carotene & xanthophyll \\
\hline Hongyihao (coral) & phytofluene & $\beta$-carotene & lycopene & $\zeta$-carotene & $\gamma$-carotene & xanthophyll \\
\hline 307Chaofeng (yellow) & phytofluene & $\beta$-carotene & lycopene & $\zeta$-carotene & - & xanthophyll \\
\hline Sanbai (white) & phytofluene & $\beta$-carotene & - & $\zeta$-carotene & - & - \\
\hline unknown & - & $\beta$-carotene & - & - & - & xanthophyll \\
\hline
\end{tabular}

Table 2. The carotenoid contents in the five different flesh colored watermelon ( $\mathrm{mg} / \mathrm{kg}$ fresh weight).

\begin{tabular}{cccc}
\hline Cultivar & $\beta$-Carotene & Lycopene & Neoxanthin \\
\hline Zaohua (red) & $4.42 \pm 0.06$ & $35.35 \pm 0.002$ & Not detected (ND) \\
307 Chaofeng (yellow) & $0.48 \pm 0.003$ & ND & $1.62 \pm 0.04$ \\
96 B 41 (pink) & $2.71 \pm 0.02$ & $21.19 \pm 0.53$ & ND \\
Sanbai (white) & ND & ND & ND \\
Hongyihao (coral) & $4.56 \pm 0.07$ & $28.44 \pm 0.03$ & ND \\
\hline
\end{tabular}


attention to with progressive understanding and great interests of the beneficial effects of lycopene in human health [11]. The lycopene content in commercial redfleshed watermelons has been reported to be $45.1-53.2$ $\mu \mathrm{g} \cdot \mathrm{g}^{-1}$ fresh weight (FW), mean value $48.2 \mu \mathrm{g} \mathrm{g}^{-1}$. These values are $60 \%$ higher than those reported for fresh tomatoes (mean value $30.2 \mu \mathrm{g} \cdot \mathrm{g}^{-1} \mathrm{FW}$ ) [12-15]. PerkinsVeazie group has systematically studied lycopene in watermelon [3,16-24]. They found that lycopene content varied widely among cultivars, in red-fleshed cultivars the highest lycopene content being $75.72 \mu \mathrm{g} \cdot \mathrm{g}^{-1} \mathrm{FW}$, the lowest $33.96 \mu \mathrm{g} \cdot \mathrm{g}^{-1} \mathrm{FW}$, and mean $50 \mu \mathrm{g} \cdot \mathrm{g}^{-1} \mathrm{FW}$ and the two yellow-fleshed varieties having $<5 \mu \mathrm{g} \cdot \mathrm{g}^{-1}$ lycopene [17]. Study on the lycopene content of 50 commercial cultivars of red-fleshed watermelon indicated that high watermelon cultivars contained $70-90 \mathrm{mg} / \mathrm{kg} \mathrm{FW}$ lycopene, very high cultivars $>90 \mathrm{mg} / \mathrm{kg} \mathrm{FW}$ lycopene, and the highest $120 \mathrm{mg} / \mathrm{kg} \mathrm{FW}$ lycopene, and that red-fleshed seedless watermelon cultivars were most often high in lycopene [3]. It is shown that triploid watermelon cultivars have more lycopene than diploid cultivars [17,24]. Yuan observed similar results [25]. They showed that diploid watermelon developed fast and accumulated more lycopene at the early stage, the lycopene of triploid and tetraploid watermelon started to increase on 20 days after pollination, then increased faster and were higher than that of diploid on $30 \mathrm{~d}$ after pollination. Seedless varieties were generally found to have higher levels of carotenoids than seeded varieties [26]. Sun compared spectrophoto-metrically lycopene content in 8 watermelon cultivars [27]. The results showed that lycopene content was $46.5-77.4 \mu \mathrm{g} \cdot \mathrm{g}^{-1} \mathrm{FW}$ in red-fleshed cultivars and smaller than $0.5 \mu \mathrm{g} \cdot \mathrm{g}^{-1} \mathrm{FW}$ in yellow-fleshed cultivars.

Besides genotype and ploidy level, lycopene content in watermelon is related to harvest maturity and growth and development conditions. Environmental conditions during production, such as light intensity, day/night temperature, irrigation, and soil fertility, can change lycopene content by $10 \%-20 \%$ [17,24]. Grafting increases lycopene in seedless watermelon [22]. Production location can also greatly affect lycopene content in watermelon [17]. Seeded watermelons generally start color development in the locule, with progressing to the center of the fruit during the ripening process. The highest lycopene occurred in the locule, followed by heart, interlecular, and rind tissues at all ripening stages. In Dixie Lee, ripe fruit had $100 \mathrm{mg} / \mathrm{kg}$ compared to $71 \mathrm{mg} / \mathrm{kg}$ lycopene in lecule and heart, respectively and 121 and 63 $\mathrm{mg} / \mathrm{kg}$ lycopene in overripe fruit [21]. Wan reported that the lycopene accumulation in red-fleshed watermelon was an S-type curve during fruit development [28]. The lycopene content of young fruit was low, and slow accumulation during fruit development, then increased dramatically with the red flesh coloring and achieved the highest value at ripening stage. Decreasing tendency in lycopene contents was observed during overripening.

\section{EFFECT OF GENETIC FACTORS ON COLOR FORMATION IN WATERMELON FLESH}

\subsection{Genetic Studies on the Flesh Coloration Patterns}

Genetic studies on watermelon flesh colors revealed that only a few gene loci were associated with color determination, each having two or three alleles. Red, orange, and salmon yellow flesh colors are controlled by $Y$, $y^{\mathrm{o}}$, and $y . Y$ (red) is dominant to both $y^{\mathrm{o}}$ (orange) and $y$ (salmon yellow), and $y^{\circ}$ (orange) is dominant to $y$ (salmon yellow) [29]. Shimotsuma suggested using cultivated and noncultivated, bitter-fruited forms of $C$ lanatus that two gene loci with epistatic interaction controlled white, yellow, and red flesh [30]. Wf (white) was epistatic to the locus $b$. The recessive allele $w f$ produced yellow flesh in combination with $B$ and red flesh $b$. Based on flesh color ratio obtained in the $F_{2}$ generation of a coss between white and red flesh inbred lines he proposed the genotypes of the $\mathrm{F}_{2}$ : white $==W f W f B B \_$or $W f w f b b$, yellow $==w f w f B B$, and red $==w f w f b b$. Thus it can be known that both $B$ (for yellow flesh) and $C$ (for canary yellow flesh) were dominant to red flesh and $W f$ (for white flesh) was epistatic to $B$. Navot also proposed the appearance of red color in the fruit was determined by a single recessive gene [31]. Henderson investigated the behavior of combination of flesh color alleles, $C, c, Y$, $y^{\circ}, y, I$, and $i$ in three reported gene loci using five cross: Yellow Baby (canary yellow flesh) $\times$ Tendersweet Orange Flesh (orange flesh), Yellow Doll (canary yellow flesh) $\times$ Tendersweet Orange Flesh, Yellow Baby $\times$ Golden Honey (salmon yellow flesh), Yellow Doll $\times$ Golden Honey, and Yellow Baby $\times$ Sweet Princess (red flesh) [32]. Analysis of the segregation of flesh color in the progeny of the five families indicated that the parental genotypes were as follows: Yellow Baby $=$ CCYYII, Yellow Doll $=C C Y Y I I$, Tendersweet Orange Flesh $=$ $c c y^{\circ} y^{\circ} I I$, Golden Honey = ccyyII, and Sweet Princess = ccYYii. In three alleles identified at the $y$ locus, $Y$ is dominant to $y^{\mathrm{o}}$ and $y$, and $y^{\mathrm{o}}$ is dominant to $y$. At the other two loci, $C$ (canary yellow) is dominant to $c$ (pink), $i$ is epistatic to $C$ and in combination with $Y$ produces red flesh. Furthermore, $C$ in the absence of $i$ is epistatic to $Y$, producing canary yellow flesh. Guner and Wehner updated watermelon gene list including flesh color genes, identified the cultivar or line having each gene mutant, and collected seeds of the lines [33,34]. Gusmini and Wehner confirmed that scarlet red flesh color in Dixielee and Red-N-Sweet was controlled by a single dominant 
gene Scarlet red flesh color (Scr) through two scarlet red parents crossed with coral red Angeleno Black Seeded [35]. Scarlet red flesh (Scr) produced more intense red color compared to Angeleno Black Seeded, the type line for red flesh color ( $Y$ gene). They called the original red flesh color coral red in watermelon. They also confirmed using the cross Cream of Saskatchewan (white flesh) $\times$ NC517 (canary yellow flesh, developed from Yellow Baby and Yellow Doll) that $C$ gene for canary yellow color was inherited as a single dominant gene. The inheritance of the $y$ and $W f$ genes was studied by two crosses: Golden Honey (salmon yellow flesh, $y$ gene) $\times$ Cream of Saskatchewan and Cream of Saskatchewan $\times$ Charleston Gray (nonwhite flesh, wf gene). Aberrations in the segregation of red, white, and salmon yellow flesh colors were observed in the progenies of two crosses. Some fruits had a pigmented center with white margin, patches of color in generally white flesh, colored flesh with white carpel walls, or other intermediate color combinations. Mendelian segregation patterns for flesh color were not observed in their progenies. They suggested that different genes, or tissue-specific expression of the same genes, might be involved in the pigmentation of different portions of watermelon fruit.

Based on the above report by Henderson et al., canary yellow flesh $(C)$ is influenced by a inhibitor of canary yellow $(i-C)$ where homozygous recessive $i$ - $C$ alleles results in red flesh even in the presence of $C$. Howewer, $i-C$ was not detected in the family derived from a cross between canary yellow and red parents. Bang created a family using 'Yellow Doll' (canary yellow) and 'Sweet Princess' (red, which was proposed to carry the inhibitor gene $i-C$ as parents) to confirm that $C$ and $i-C$ determine flesh color between canary yellow and red watermelon and to identify additional genetic determinants [8]. They identified a new class of flesh color, pale yellow, in F2 and backcross generations of the new family. The chi square goodness-of-fit test showed that there appeared to be two genes involved in determining flesh color between yellow (both canary and pale yellow) and red. They identified pale yellow was as a distinct phenotype and pointed out that pale yellow was controlled by a single recessive gene (py) that was only expressed in the presence of $C$ gene. Therefore, it appeared that the inhibitor of $C(i-C)$ didn't exist in the new family and suggested that $P y$ had the $C$ allele and another as of yet unidentified gene controlled the amount of yellow pigment accumulated [8]. Owing to the shortage of carotenoid profiles white flesh called in previous investigations was probably confused with pale yellow flesh in watermelon [1].

\subsection{Carotenogenic Genes and Their Expression in Watermelon Flesh}

Carotenoid biosynthetic and catabolic pathway in has been determined in other higher plants [36-41]. Herein carotenoid metabolic pathway in watermelon is proposed in Figure 1 on the basis of watermelon carotenoid composition and carotenoid-related genes cloned from watermelon and consulting carotenoid merabolic pathway in higher plants. In plastid glyceraldehy 3-phosphate and pyruvate are converted into geranylgeranyl pyrophosphate via methylerythritol phosphate (MEP), isopentenyl pyrophosphate (IPP), and dimethylallyl pyrophosphate (DMAPP). The first committed step, mediated by phytoene synthase (PSY), is a head-to-head condensation of two molecules of geranylgeranyl pyrophosphate (GGPP) to form colorless 15-cis-phytoene. Subsequently, four additional double bonds are introduced by desaturases, producing phytofluene, $\zeta$-carotene, neurosporene, and lycopene. Two cis-trans isomerases of Z-ISO and CRTISO are required to catalyze the isomerization of poly-ciscarotenoids to all-trans-carotenoids during desaturation. Lycopene is the branching point of this pathway. Lycopene cyclisation produces $\alpha$-carotene by lyco- pene $\varepsilon$-cyclase (LCYE) and lycopene $\beta$-cyclase (LCYB) or $\beta$-carotene by lycopene $\beta$-cyclase (LCYB) alone. The occurrence of lycopene $\varepsilon$-cyclase (LCYE) in watermelon has been not yet identified. $\alpha$-Carotene and $\beta$-carotene are hydroxylated to produce lutein and zeaxanthin via $\beta$ cryptoxanthin, respectively. Furthermore, zeaxanthin is epoxidated to produce violaxanthin via antheraxanthin. Violaxanthin is converted into neoxanthin. Carotenoids are metabolized to apocarotenoids through the pathway catalyzed by carotenoid cleavage dioxygenases. CCD1 catalyzes symmetrical $9-10$ and $9^{\prime}-10^{\prime}$ cleavages of multiple carotenoid substrate. Nine-cis-epoxycarotenoid dioxygenase (NCED) catalyzes the cleavage of 9-cisviolaxathin or 9-cis-neoxanthin to yield a $\mathrm{C}_{25}$ epoxycarotenal and xanthoxin $\left(\mathrm{C}_{15}\right)$, a precursor of ABA [42].

The cloning of carotenogenic genes may provide better understanding of the characterization of carotenoid biosynthetic pathway and the elucidation of the each gene functions and their relationship to the specific phenotype occurrence and a prerequisite for engineering of carotenoid formation in a variety of crops. Up to now genes encoding enzymes in carotenoid metabolism have be cloned from many plant species, such as tomato, Arabidopsis (Arabidopsis thaliana), pepper, Citrus fruit, and so on [43-45]. Bang isolated a total of eight fulllength cDNAs encoding enzymes in the carotenoid biosynthetic pathway from watermelon: phytoene synthase

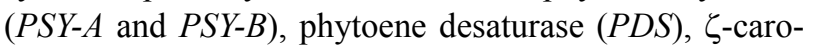
tene desaturase $(Z D S)$, carotenoid isomerase (CRT-ISO), lycopene $\beta$-cyclase $(L C Y B), \beta$-carotene hydroxyl-lase $(C H Y B)$, and zeaxanthin epoxidase (ZEP) [46]. She examined differential expression of these genes across different colored fleshes at the transcriptional level. The results showed that $P S Y-A$ was expressed in various 


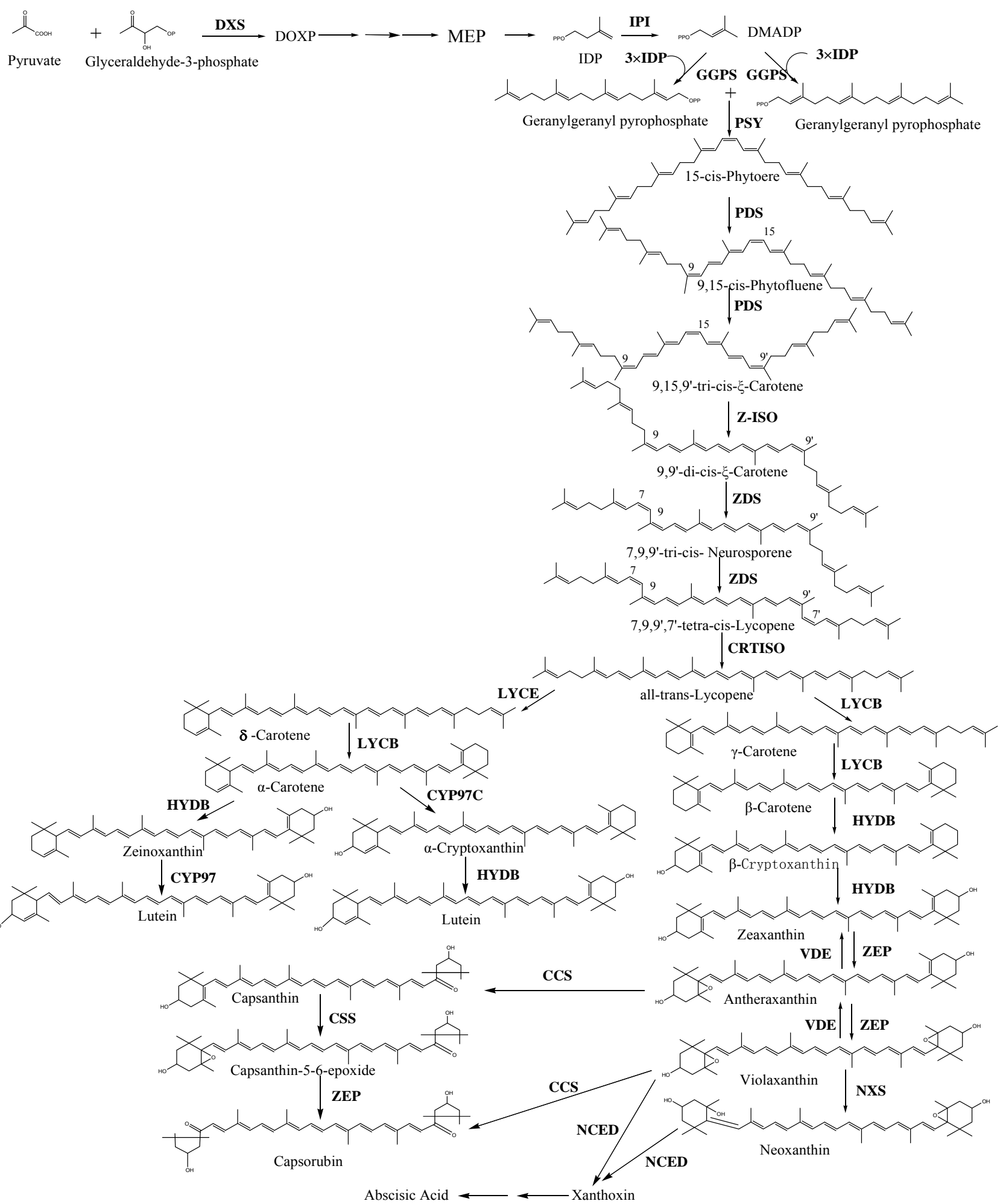

Figure 1. Carotenoid biosynthetic pathway in higher plants. Abbreviations: DXP, 1-deoxy-D-xylulose 5-phosphate synthase; DOXP, 1-deoxy-D-xylulose 5-phosphate; MEP, 2-C-methyl-D-erythritol 4-phosphate; IDP, isopentenyl diphosphate; IPI, isopentenyl diphosphate isomerase; DMADP, dimethylallyl diphosphate; GGPP, geranylgeranyl diphosphate; GGPPS, GGPP synthase; PSY, phytoene synthase; PDS, phytoene desaturase; Z-ISO, zeta-carotene isomerase; ZDS, zeta-carotene desaturase; CRTISO, carotenoid isomerase; LYCB, lycopene beta-cyclase; LYCE, lycopene epsilon-cyclase; CCS, capsanthin-capsorubin synthase; CYP97C, carotene epsilon-ring hydroxylase; HYDB, beta-carotene hydroxylase (BCH, CYP97A or CYP97B); ZEP, zeaxanthin epoxidase; VDE, violaxanthin de-epoxidase; NXS, neoxanthin synthase; NCED, 9-cisepoxycarotenoid dioxygenase. 
fleshes and did not show differential expression across flesh colors. $P S Y-B$ transcript was not detected in any flesh color and observed only in ovary, leaf, and root tissues, similar to $P S Y 2$ of tomato. The gene expression of CRTISO was not detected in salmon yellow-fleshed fruit and appeared to be at slightly low level in orange flesh. Any differential expression of other genes except CRTISO was not detected across five colored fleshes (white, canary yellow, salmon yellow, orange, and red). Through a LCYB CAPS marker analysis of the segregation of the flesh color in the progeny of the cross between canary yellow and red she indicated that single gene might determine the flesh color difference. Since canary yellow was known to be dominant to red, it seemed likely that early steps from $P S Y$ to $Z D S$ in both canary yellow and red flesh pigment formation pathway might be active to red lycopene. A possible candidate gene for the color determinant would be the gene downstream of the pathway. Moreover, she showed that the mutation of $L C Y B$ in watermelon seemed to account for lycopene accumulation and significant $\beta$-carotene reduction in red flesh. $L C Y B$ was identified to be a key gene for color differentiation between canary yellow and red fleshes in watermelon. The significant differential expression of the gene was not detected at the transcriptional level. Furthermore, Bang reported a single nucleotide polymorphism (SNP) in the coding region of the $L C Y B$ gene by comparing the sequences of genomic DNAs from canary yellow and red watermelon [47]. Three SNPs in the coding region of $L C Y B$ was identified between canary yellow and red fleshes. One of the SNPs introduces an amino acid replacement of evolutionarily conserved Phe226 to Val. These SNPs showed perfect co-segregation with flesh color phenotypes. Their results suggested that $L C Y$ may be the genetic determinant for canary yellow or red flesh color. Thereby $L C Y$ was linked with $C$ gene reported before. A single recessive $p y$ expressed in the presence of $C$ allele led to pale yellow phenotype [8]. Guo et al. studied transcriptome dynamics at four watermelon fruit developmental stages (immature white, white-pink flesh, red flesh and over-ripe) and suggested that the up-regulation of $P S Y 1$ could generate a flux of carotenoids and the down-regulation of $L C Y B$ create a blockade downstream, leading to the accumulation of lycopene. They concluded that PSY 1 and LCYB were key enzymes controlling carotenoid content in watermelon fruits [48].

Eleven cDNA fragments for carotenoid-related genes were cloned from watermelon in our laboratory. They are: geranylgeranyl pyrophosphate synthase (GGPPS, complete CDS 1445bp, unpublished), PSY (DQ494214, partial CDS 747bp; complete CDS $1561 \mathrm{bp}$, unpublished), PDS (EF159942, partial CDS 921bp), ZDS (GQ140241), CRTISO (FJ788510), LCYB (EF014290), CHYB (FJ99804
5), and nine-cis-epoxycarotenoid dioxygenase (NCED1, FJ998046; NCED2, FJ998047; and NCED3, FJ998048). The watermelon $P S Y$ fragment shares $97.8 \%$ identity with melon PSY, 94\% with Momordica charantia PSY, and $90.3 \%$ with citrus $P S Y$ [49], but only $59.2 \%$ with $P S Y-A$ and $55.8 \%$ with $P S Y-B$ cloned by Bang [46]. cDNA fragments for PDS, ZDS, CRTISO, $L C Y B$, and $C H Y B$ show over $90 \%$ identity with the corresponding genes reported by Bang [46]. There is over $80 \%$ identity between watermelon $C C D$ and grape and citrus $C C D$. Three watermelon $N C E D$ s share high identity with Arabidopsis thaliana $N C E D$, maize $V p 14$, rice $N C E D$, and citrus $N C E D$. The expression pattern of ten genes except GGPPS was preliminarily analyzed at three fruit developmental stages $(10,20$, and 30 days postanthesis) in five flesh colors of watermelon cultivars (red, pink, orange, yellow, and white). The results showed that these gene transcripts were detected at three fruit developmental stages in five cultivars. Most genes were expressed in a similar pattern during the watermelon fruit growth in red- and pink-fleshed watermelons. Gene expression increased during the early stages of fruit development and subsequently decreased until the fruit ripened. Transcript levels of $P D S$ increased gradually and reached a maximum at $30 \mathrm{~d}$ after pollination. Alternatively, ZDS and CRTISO transcript levels decreased and reached a minimum at fruit ripening. Expression of $L C Y B$ and $C H Y B$ clearly increased during fruit early development and reduced dramatically at $30 \mathrm{~d}$ postanthesis. The amount of transcript level variation among the three developmental stages was different in red- and pinkfleshed cultivars. Compared to the red-fleshed cultivars, high transcript levels were detected throughout the investigation for almost all the genes in yellow-fleshed watermelon. Furthermore, gene expression remained at high levels at $30 \mathrm{~d}$ postanthesis, although this cultivar accumulated small amounts of carotenoids. The expression levels of all genes in white-fleshed watermelon were no less than those in other colored cultivar at the beginning of fruit development. Afterwards, gene expression decreased dramatically and was clearly lower than those of the other cultivars. At the late stage of development, the transcripts were hardly detected at 30 day postanthesis [5].

Chromatographic analysis showed that lutein was present in watermelon fruit. Gene activity of LCYE which catalyzes lutein formation was not yet detected in the fruits sampled. Little is known about the cause yet, gene deletion or expression repression?

\section{SUMMARY}

Carotenoids are responsible for the different flesh colors in watermelon fruit. The multiple flesh colors in watermelon fruit are due to the intrinsic regulatory mecha- 
nisms of carotenoid metabolic pathway leading to accumulation of specific major carotenoids. However, few studies have been carried out with regard to carotenoid metabolism in watermelon at molecular level, although great advances have been made in analysis of carotenoids in watermelon.

Although the search for carotenogenic genes continues, the current status of carotenoid research is somewhat restricted by its reliance on the gene-by-gene approach to metabolic engineering. In other pathways, the focus has shifted away from individual genes or collections thereof and towards overarching regulatory mechanisms that may allow multiple genes in the pathway to be controlled simultaneously. The multiple flesh colors available in watermelon fruit makes it ideal for investigating the regulation of these other carotenoids. The intrinsic regulatory mechanisms that operate within the pathway and have hindered optimal biosynthetic capacity will hopefully be addressed.

\section{REFERENCES}

[1] King, S.R., Davis, A.R. and Bang, H. (2009) New flesh colors in watermelon? HortScience, 44, 576.

[2] Tadmor, Y., King, S., Levi, A., Davis, A., Meir, A., Wasserman, B., Hirschberg, J. and Lewinsohn, E. (2005) Comparative fruit colouration in watermelon and tomato. Food Research International, 38, 837-841. doi:10.1016/i.foodres.2004.07.011

[3] Perkins-Veazie, P., Collins, J.K., Davis, A.R. and Roberts, W. (2006) Carotenoid content of 50 watermelon cultivars. Journal of Agricultural and Food Chemistry, 54, 25932597. doi:10.1021/jf052066p

[4] Jia, G., Zhao, W., Shen, H., Wang, B. and Ma, S. (2008) Analysis of carotenoids in watermelon by column chromatography separation. Journal of Anhui Agricultural Sciences, 36, 8416-8418. (in Chinese)

[5] Kang, B., Zhao, W., Hou, Y. and Tian, P. (2010) Expression of carotenogenic genes during the development and ripening of watermelon fruit. Scientia Horticulturae, 124, 368-375. doi:10.1016/j.scienta.2010.01.027

[6] Hu, L. (2009) Separation and analysis of carotenoids in watermelon. Ms.D. Thesis, Zhengzhou University, Zhengzhou. (in Chinese)

[7] Hu, L., Guo, X., Zhao, W., Wang, J. and Zhang, G. (2011) Separation and analysis of carotenoids in watermelon flesh. Journal of Henan Agricultural Sciences, 40, 150156. (in Chinese)

[8] Bang, H., Davis, A., Kim, S., Leskovar, D. and King, S. (2010) Flesh color inheritance and gene interactions among canary yellow, pale yellow, and red watermelon. Journal of the American Society for Horticultural Science, 135, 362-368.

[9] Liu, C., Zhang, H., Dai, Z., Liu, X., Liu, Y., Deng, X., Chen, F. and Xu, J. (2012) Volatile chemical and carotenoid profiles in watermelons [Citrullus vulgaris (Thunb.)
Schrad (Cucurbitaceae)] with different flesh colors. Food Science and Biotechnology, 21, 531-541. doi:10.1007/s10068-012-0068-3

[10] Hui, B. and Li, J. (2008) Content and composition comparisons of carotenoids between red-flesh watermelon and yellow-flesh watermelon. Food Science, 29, 587-591. (in Chinese)

[11] Collins, J.K., Perkins-Veazie, P. and Roberts, W. (2006) Lycopene: From plants to humans. HortScience, 41, 1135-1144.

[12] USDA-NCC (1998) Carotenoid database for US foods. http://www.nal.usda.gov/fnic/food

[13] Heinonen, M.I., Ollilainen, V., Linkola, E.K., Varo Pertti, T. and Koivistoinen, P.E. (1989) Carotenoids in Finnish foods: vegetables, fruits and berries. Journal of Agricultural and Food Chemistry, 37, 655-659. doi:10.1021/jf00087a017

[14] Holden, J.M., Eldridge, A.L., Beecher, G.R., Buzzard, I.M., Bhagwat, S., Davis, C.S., Douglass, L.W., Gebhardt, E.S, Haytowitz, D. and Schakel, S. (1999) Carotenoid Content of U.S. foods: An update of the database. Journal of Food Composition and Analysis, 12, 169-196. doi:10.1006/jfca.1999.0827

[15] US Department of Agriculture, ARS (2005) USDA National Nutrient Database for Standard Reference, release 18. US Department of Agriculture, Washington DC.

[16] Perkins-Veazie, P., Collins, J.K. and Pair, S.D. (2000) Watermelon lycopene content varies with cultivar and maturity stage. HortScience, 35, 412.

[17] Perkins-Veazie, P., Collins, J.K., Pair, S.D. and Roberts, W. (2001) Lycopene content differs among red-fleshed watermelon cultivars. Journal of the Science of Food and Agriculture, 81, 983-987. doi:10.1002/jsfa.880

[18] Perkins-Veazie, P., Roberts, W., Collins, J.K. and Perez, K. (2003) Lycopene variation among watermelons: Culivars, potassium, and ripeness. HortScience, 38, 1295.

[19] Perkins-Veazie, P. and Collins, J.K. (2004) Flesh quality and lycopene stability of fresh-cut watermelon. Postharvest Biology and Technology, 31, 159-166. doi:10.1016/j.postharvbio.2003.08.005

[20] Perkins-Veazie, P. and Collins, J.K. (2006) Carotenoid changes of intact watermelons after storage. Journal of Agricultural and Food Chemistry, 54, 5868-5874. doi:10.1021/jf0532664

[21] Perkins-Veazie, P. (2007) Ripening events in seeded watermelons. Hort Science, 42, 927.

[22] Perkins-Veazie, P. and Zhang, X. (2007) Grafting increases lycopene in seedless watermelon. HortScience, 42, 959.

[23] Davis, A.R., Fish, W.W. and Perkins-Veazie, P. (2003) A rapid hexane-free method for analyzing lycopene content in watermelon. Journal of Food Science, 68, 326-332. doi:10.1111/j.1365-2621.2003.tb14160.x

[24] Leskovar, D.I., Bang, H., Crosby, K.M., Maness, N., Franco, J.A. and Perkins-Veazie, P. (2004) Lycopene, carbohydrates, ascorbic acid and yield components of diploid and triploid watermelon cultivars and affected by deficit irrigation. Journal of Horticultural Science and Biotechnology, 79, 75-81. 
[25] Yuan, P., Liu, W., Lu, X., Zhao, S., Lu, J., Yan, Z., He, N., Zhu, H. and Guan, L. (2012) Change of lycopene contents during fruit development of different ploidy watermelon. Journal of Fruit Science, 29, 890-894. (in Chinese)

[26] Jeffery, J., Davis, A. and King, S. (2012) Understanding the carotenoid biosynthetic pathway: Observation of four color variants of developing watermelon fruit. Israel Journal of Plant Sciences, 60, 425-434.

[27] Sun, L., Ding, S., Li, J., Zhu, F. and Wang J. (2006) Comparative analysis of lycopene contents among 8 watermelon cultivars. Acta Agriculturae Shanghai, 22, 66-68. (in Chinese)

[28] Wan, X., Liu, W., Yan, Z., Zhao, S., He, N., Liu, P. and Dai, J. (2011) Changes of the contents of functional substances including lycopene, citrulline and ascorbic acid during watermelon fruits development. Scientia Agricultura Sinica, 44, 2738-2747. (in Chinese)

[29] Henderson, W.R. (1989) Inheritance of orange flesh color in watermelon. Cucurbit Genetics Cooperative Report, 12, 59-63.

[30] Shimotsuma, M. (1963) Cytogenetical studies in the genus Citrullus. VII. Inheritance of several characters in wtaremelons. Japanese Journal of Breeding, 13, 235-240.

[31] Navot, N., Sarfatti, M. and Zamir, D. (1990) Linkage relationships of genes affecting bitterness and flesh color in watermelon. Journal of Heredity, 81, 162-165.

[32] Henderson, W.R., Scott, G.H. and Wehner, T.C. (1998) Interaction of flesh color genes in watermelon. Journal of Heredity, 89, 50-53. doi:10.1093/jhered/89.1.50

[33] Guner, N. and Wehner, T.C. (2004) The genes of watermelon. HortScience, 39, 1175-1182.

[34] Wehner, T.C. (2008) Overview of the genes of watermelon. Proceedings of the IXth EUCARPIA Meeting on Genetics and Breeding of Cucurbitaceae, Avignon, 21-24 May 2008, 79-89.

[35] Gusmini, G. and Wehner, T.C. (2006) Qualitative inheritance of rind pattern and flesh color in watermelon. Journal of Heredity, 97, 177-185. doi:10.1093/jhered/esj023

[36] Hirschberg, J. (2001) Carotenoid biosynthesis in flowering plants. Current Opinion in Plant Biology, 4, 210-218. doi:10.1016/S1369-5266(00)00163-1

[37] Fraser, P.D. and Bramley, P.M. (2004) The biosynthesis and nutritional uses of carotenoids. Progress in Lipid Research, 43, 228-265. doi:10.1016/j.plipres.2003.10.002

[38] Sadmann, G., Römer, S. and Fraser, P.D. (2006) Understanding carotenoid metabolism as a necessity for genetic engineering of crop plants. Metabolic Engineering, 8,
291-302. doi:10.1016/j.ymben.2006.01.005

[39] Li, F.Q., Murillo, C. and Wurtzel, E.T. (2007) Maize Y9 encodes a product essential for 15-cis-zeta-carotene isomerization. Plant Physiology, 144, 1181-1189. doi:10.1104/pp.107.098996

[40] Christopher, I.C. and Barry, J.P. (2010) Source to sink: Regulation of carotenoid biosynthesis in plants. Trends in Plant Science, 15, 266-274. doi:10.1016/j.tplants.2010.02.003

[41] Zhao, W. (2011) Natural pigments for use in foods. Encyclopedia of biotechnology in agriculture and food. Taylor \& Francis, London.

[42] Auldridge, M.E., McCarty, D.R. and Klee, H.J. (2006) Plant carotenoid cleavage oxygenases and their apocarotenoid products. Current Opinion in Plant Biology, 9, 315-321. doi:10.1016/j.pbi.2006.03.005

[43] Cunningham Jr., F.X. and Gannt, E. (1998) Genes and enzymes of carotenoid biosynthesis in plants. Plant Physiology and Plant Molecular Biology, 49, 557-583. doi:10.1146/annurev.arplant.49.1.557

[44] Sauret-Gueto, S., Botella-Pavia, P. and Rodríguez-Concepción, M. (2003) Molecular tools for the metabolic engineering of carotenoid biosynthesis in plants. Recent Research Developments in Plant Molecular Biology, 1, 339-363.

[45] Kato, M., Ikoma, Y., Matsumoto, H., Sugiura, M., Hyodo, H. and Yano, M. (2004) Accumulation of carotenoids and expression of carotenoid biosynthetic genes during maturation in citrus fruit. Plant Physiology, 134, 824-837. doi:10.1104/pp.103.031104

[46] Bang, H. (2005) Environmental and genetic strategies to improve carotenoids and quality in watermelon. Ph.D. Thesis, Texas A\&M University, College Station.

[47] Bang, H., Kim, S., Leskovar, D. and King, S. (2007) Development of a codominant CAPS marker for allelic selection between canary yellow and red watermelon based on SNP in lycopene $\beta$-cyclase (LCYB) gene. Molecular Breeding, 20, 63-72. doi:10.1007/s11032-006-9076-4

[48] Guo, S., Liu, J., Zheng, Y., Huang, M., Zhang, H., Gong, G., He, H., Ren, Y., Zhong, S., Fei, Z. and Xu, Y. (2011) Characterization of transcriptome dynamics during watermelon fruit development: Sequencing, assembly, annotation and gene expression profiles. BMC Genomics, 12, 454. doi:10.1186/1471-2164-12-454

[49] Kang, B. and Zhao, W. (2007) Isolation and characterization of a watermelon partial cDNA ecoding phytoene synthase gene. Acta Botanica Boreali-Occidentalia Sinica, 27, 908-911. (in Chinese) 